\title{
EDITORIAL
}

\section{DOSSIÊ DOCÊNCIA NA EDUCAÇÃO PROFISSIONAL}

\author{
Profa. Dra. Ana Lucia Sarmento Henrique \\ Profa. Da. Ilane Ferreira Cavalcante \\ Profa. Dra. Olivia Morais de Medeiros Neta \\ Prof. Dr. Dante Henrique Moura
}

DOI: $10.15628 /$ rbept.2017.5855

Digo: o real não está na saída nem na chegada: ele se dispõe para a gente é no meio da travessia. (Guimarães Rosa. Grande Sertão: veredas).

A realidade constitui-se do caminho que cada um traça a partir de sua formação, de sua vivencia familiar, de sua prática profissional, enfim, das especificidades de sua caminhada. A realidade, como afirma Guimarães Rosa, está mesmo nesse caminho, no meio da travessia. E é sobre esse caminhar, aqui pensado no sentido da formação docente, que esse dossiê se debruça, apresentando experiências de pesquisa junto a turmas da pós-graduação em Educação Profissional do Instituto Federal de Educação, Ciência e Tecnologia do Rio Grande do Norte (IFRN), assim como textos de pesquisadores de outras instituições, que também pensam a docência na educação profissional na rede federal e nas instituições privadas.

[...] pode-se admitir que a prática implica sempre uma operação de conhecimento, isto é, uma operação mais ou menos complexa de classificação, que nada tem em comum com um registro passivo. (BOURDIEU; SAINT-MARTIN, 2011, p. 187).
Como professoras de um programa de Pós-graduação em Educação Profissional, interessa-nos conhecer a realidade da docência nessa modalidade, e também possibilitar momentos para que nossos estudantes também a conheçam. Nesse sentido, e buscando uma formação que estabeleça uma práxis voltada para a pesquisa, é que este nossa prática se debruça sobre a realização de pesquisas voltadas para os sujeitos da rede pública e particular de educação profissional.

A ideia de realizar pesquisas no processo de formação docente tomou lugar durante a disciplina de Formação Docente para a Educação Profissional, no Programa de Pósgraduação em Educação Profissional (PPGEP) do IFRN. Nessa disciplina, em geral é proposta a realização de uma reflexão sobre a própria formação (ensaio auto-formativo) ou uma pesquisa sobre a realidade da docência na Educação profissional.

A pesquisa surgiu como uma experiência a ser desenvolvida no processo de formação, pois, como afirmam Ghedin e Franco, é a experiência que liga a teoria à prática em um elo indissociável.

A experiência é um dizer-se sem saber dizer de si, isto é, a confluência e a coincidência entre o ser e o agir. Ela é aquela tênue ligação que se dá entre a teoria e a prática, entre a ciência e a técnica, entre a ideologia e a política, 
entre a fé e o dogma, entre o ser e o querer ser. Pode-se dizer que ela é o hiato que liga nosso limite a todas as possibilidades infinitas que temos de ser. É justamente a experiência que nos permite a reflexão crítica. Isto ocorre porque ela não é nem pensamento e nem ação, mas a possibilidade de pensar duplamente sobre nossas formas de agir e instituir as práticas que nos constituem. (GHEDIN; FRANCO, 2006, p.11).

As experiências aqui apresentadas compreendem 2 anos de trabalho junto a duas turmas do Programa de Pós-Graduação. A primeira pesquisa foi realizada entre professores de três campi do Curso Técnico Integrado em Informática do IFRN. A segunda pesquisa se debruçou sobre a rede particular de educação profissional, escolhendo duas instituições que abriram suas portas aos estudantes do programa para a realização da pesquisa.

Nessa segunda pesquisa, foram escolhidos como locus da pesquisa o Curso Técnico Subsequente em Enfermagem de uma instituição e os cursos Técnicos Subsequentes em Análises Clínicas e em Radiologia de outra instituição. A escolha, portanto, recaiu sobre a área da saúde, por haver, entre os estudantes do programa, profissionais que atuavam nessas instituições e nessa área, que poderiam proporcionar maior abertura para a realização da pesquisa.

As pesquisas se configuraram como um trabalho colaborativo (entre professoras da disciplina e professores em formação na pósgraduação) e foi sendo construída no cotidiano da sala de aula. Sob a perspectiva das professoras, o trabalho se constituía em organizar as discussões, direcionar os trabalhos dos grupos, definir prazos e avaliar o desenvolvimento do trabalho que, posteriormente, se materializaria em uma série de artigos com os resultados da pesquisa, propostos como atividade final da disciplina em curso.

Referente à experiência de pesquisa vivenciada junto à primeira turma, temos o artigo A experiência da pesquisa na formação docente: unindo teoria à prática que é uma reflexão sobre a primeira experiência da pesquisa na disciplina Formação de Professores para a Educação Profissional cujos artigos, com os resultados desse trabalho compõem este dossiê. Tentando unir teoria à prática, objetivou-se, na disciplina, a integração do conteúdo a ser ministrado em sala de aula com a experiência mesma do fazer científico na perspectiva de que o trabalho final da disciplina se revestisse de um caráter científico-reflexivo, ao mesmo tempo, inovador e que levasse também à produção de conhecimento na área.

Para o artigo Identidade Docente de Professores do Ensino Médio Integrado do IFRN: entre a paixão e o acaso as autoras elegeram como categoria geral de pesquisa o perfil do docente, a formação de sua identidade docente. A partir dessa categoria mais geral, elas elegeram as três categorias mais recorrentes nos depoimentos dos sujeitos, como aquelas que seriam abordadas em seu estudo sobre a identidade dos docentes pesquisados: percepção sobre a formação para a docência; relação prévia com a docência e momentos-charneira. As três categorias trabalhadas ajudaram a compreender aspectos da identidade dos docentes entrevistados, cada uma deixando entrever os desenhos das tramas narradas. A primeira dá pistas sobre como cada professor relaciona sua própria formação e sua atuação profissional; a segunda indica os caminhos traçados antes da opção pela docência; a terceira permite confrontar esses caminhos anteriores e os hoje percorridos. A conclusão a que as autoras chegam é que um elemento 
bastante recorrente às narrativas analisadas é a ausência de planos de mudança profissional. À exceção de um, nenhum professor manifestou a possibilidade de deixar de ser professor. De alguma forma, por algum caminho, a docência seduziu esses sujeitos. Nessa sedução devem pesar muitos fatores de ordem objetiva e subjetiva. A estabilidade do serviço público, as condições de trabalho e o plano de carreira. Tenham sonhado com a docência desde a infância, se apaixonado por ela já adultos ou aceitado a docência como um ganha-pão possível, esses professores se renderam ao ofício de professor, assumindo um relacionamento com ele até que a aposentadoria os separe.

No artigo A Formação Docente para a EPT: um estudo sobre a percepção de formação integral e integrada dos professores do curso de informática do IFRN, as autoras se debruçam sobre uma segunda categoria geral de interesse da pesquisa realizada: a compreensão que esses docentes demonstram acerca de alguns princípios e conceitos presentes no Projeto Político Pedagógico do IFRN, concernentes à Educação Profissional e ao Nível Médio Integrado. Na conclusão de seu artigo, as autoras mostram que, segundo seus sujeitos, não há ainda uma apropriação epistemológica das concepções de formação integral e integrada, bem como sua efetivação nas práxis desses sujeitos apesar de demonstrarem uma intencionalidade de aceitação e adoção destas concepções em seu fazer.

O artigo Concepções Docentes: práticas pedagógicas integradoras e os desafios para sua Implementação no IFRN, volta-se para a categoria geral das práticas docentes, as autoras concluem que a prática pedagógica ainda ocorre de maneira desarticulada do contexto de integração com as demais áreas do conhecimento e, quando essa integração acontece, na maioria das vezes, é no âmbito dos próprios núcleos ou em atividades pontuais como aula de campo, projeto integrador e outras ações acadêmicas isoladas.

O artigo Formação e Saberes Docentes na Educação Profissional: um relato de experiência objetiva analisar, a partir das concepções dos docentes do EMI de Informática, a necessidade de uma formação docente específica para atuar na educação profissional. A análise dessa temática coloca em evidência, ao longo da pesquisa, que é necessário buscar uma nova proposta de formação docente na educação profissional para os professores que atuam no IFRN, pois estes mostram, por meio de suas falas, que encontram obstáculos na prática docente para atuar nessa modalidade de ensino. Uns acreditam que é necessária uma formação para aqueles de áreas específicas, outros afirmam que essa formação é necessária a todos os profissionais que atuam como docentes em instituições que atuam na EP. Sendo assim, faz-se necessária uma formação e saberes específicos para atuar na educação profissional, para que seja possível entendê-la não como um simples instrumento de política assistencialista ajustado às demandas do mercado de trabalho e às necessidades do capital, mas como importante estratégia para que os cidadãos tenham efetivo acesso às conquistas científicas e tecnológicas existentes na sociedade.

Para complementar esse ciclo reflexivo, - artigo A Educação Profissional na Rede Federal de Educação Tecnológica sob o enfoque do trabalho na organização Taylorista/Fordista, de autoria de pesquisadores do IFRN, da UFRN e da Universidade do Porto, faz uma reflexão acerca da formação profissional a ser empreendida em escola técnica tendo como categoria base de análise o trabalho na sua organização taylorista /fordista. A partir da análise do trabalho no Brasil no século XX, enfatizando os 
anos de início da industrialização, observa-se o papel da escola industrial e técnica face às exigências do capital. Concluem que a formação profissional expressa pela arquitetura curricular comum à Rede de EPT se apresenta calcada em especialidades de diversos ramos da produção e, em função disso, intensifica-se a desqualificação do trabalhador e amplia-se o processo de especialização.

Referente à segunda experiência de pesquisa junto à turma, o artigo Desvelando o percurso formativo de docentes da Educação Profissional: um estudo de caso com professores do curso de análises clínicas de uma IES privada, objetiva apresentar os desvelamentos do percurso formativo de dois professores de disciplinas específicas que atuam na Educação Profissional (EP), do Curso de Análises Clínicas, de uma IES privada do estado do Rio Grande do Norte. Os autores chegam à conclusão de que esses professores não possuem formação específica em licenciatura ou formação didática pedagógica para lecionar na Educação Profissional, assim, mobilizam os saberes técnicos da área e não do ensino e aprendizagem adquiridos nas formações docentes inicial e continuada.

O artigo Percepção da relação Teoria e Prática no trabalho docente: um estudo com professores da área da saúde objetiva identificar a percepção do docente em relação à teoria e à prática em sala de aula nos cursos técnicos de enfermagem, Radiologia e Análises Clínicas. Os autores concluíram que, entre os sujeitos entrevistados, a maioria acredita que a relação teoria e prática na formação docente na educação profissional são essenciais e que a prática depende da teoria, bem como a teoria depende da prática.

Nesse mesmo sentido, 0 artigo $A$ relação teoria e prática: investigando as compreensões de professores que atuam na Educação Profissional, que tem como objetivo compreender a relação teoria e prática no trabalho de professores de formação geral que atuam na educação profissional na rede particular de ensino, chega à conclusão de que a compreensão dos professores demonstra uma prevalência da visão dicotômica da relação teoria e prática na atuação docente da formação técnica profissional.

Os artigos O caminho dos professores na Educação Profissional: percepções sobre o sentido do trabalho e do trabalho docente e Sobre trabalho e trabalho docente: a percepção de docentes da área de formação geral analisam os conceitos de trabalho e trabalho docente de professores que atuam na EP da rede particular. Os autores do primeiro artigo observam que os professores concebem o trabalho docente de forma distinta de outros tipos de trabalho, todavia, não conseguem sinalizar quais saberes são específicos da prática docente. Já as autoras do segundo artigo identificam que os docentes pesquisados não compreendem o trabalho e o trabalho docente em sua essência, embora essa compreensão seja relevante para sua atuação na Educação Profissional.

O artigo O Perfil de formação de professores da Educação Profissional que atuam em instituições privadas no RN: uma análise a partir das vozes dos docentes do eixo da formação geral analisa o perfil de formação de professores de disciplinas do eixo geral de duas instituições que ofertam cursos de Educação Profissional subsequente ao ensino médio na área de saúde no Rio Grande do Norte. Os resultados do estudo permitiram apontar para um perfil de formação bastante variada. As autoras chegam à conclusão de que os conhecimentos relativos à compreensão do funcionamento da sociedade e das relações entre trabalho, cultura, ciência e Estado, das políticas públicas e dessas, articuladas à educação profissional, além de não serem contempladas na formação inicial dos 
professores investigados também não constituem objeto de estudo na formação continuada promovida pelas instituições.

$\mathrm{O}$ artigo A Educação Profissional e Tecnológica na modalidade a distância: história, bases legais e cursos nessa modalidade de ensino, de pesquisadoras da Universidade Estadual de Maringá, objetiva discorrer sobre os aspectos históricos e legais da educação profissional e tecnológica a distância, além de apresentar o desenvolvimento dos cursos dessa modalidade de ensino em algumas instituições, como o Instituto Monitor, o Instituto Universal Brasileiro, o Telecurso e a Rede e-TEC, demonstrando a importância dessas práticas de ensino e aprendizagem, por se configurar como uma estratégia de expansão do ensino que possibilita a formação dos sujeitos ao longo da vida.

Finalizando essa apresentação, é importante pensar que

A profissionalização do professor está diretamente ligada ao exercício de sua prática profissional, a que está condicionada por uma rede de relações de poder. Se a prática é um processo constante de estudo, de reflexão, de discussão, de experimentação, conjunta e dialeticamente com o grupo de professores, se aproximará da tendência emancipadora, crítica, assumindo um determinado grau de poder que repercute no domínio de si mesmos. (IMBERNÓN, 2011, p. 36).

Essa aproximação à pesquisa, proposta para as duas turmas da disciplina Formação de Professores para Educação Profissional, de forma específica, tem o discente (que também é professor) como sujeito produtor do conhecimento e, na medida em que ele pesquisa a formação e atuação de outros docentes, produz conhecimento e se (re)conhece como partícipe de uma comunidade profissional, ao mesmo tempo em que se forma como profissional.

Quando se trata da Educação Profissional (EP), modalidade pouco estudada na formação inicial (como a outras modalidades da educação brasileira), essa participação em pesquisa, entendida aqui como espaço de formação, é fundamental para a continuidade da formação do docente de EP.

Portanto, os artigos apresentados neste dossiê, ao mesmo tempo em que são a materialização da pesquisa como espaço de formação, lançam olhares múltiplos e plurais sobre a Educação Profissional e, em especial, sobre práticas de ensino e aprendizagem e sobre a docência. 